\title{
Vascular dementia: current considerations
}

\begin{abstract}
Vascular dementia (VaD) is the second neuropathology that causes dementia in older adults, a reason for this classification, diagnosis and management of the child of great importance worldwide. It is classified into: dementia of multiple infarctions, post-stroke dementia, subcortical ischemic vascular pathology, dementia due to small vessel disease, dementia of hypoperfusion and hereditary vascular dementia. Contrary to what is thought, today this pathology is a problem due to partial ignorance of its pathogenesis, where Alzheimer's disease could be participating, thus constituting a mixed dementia. Combined, there is no treatment that stops its progressive progress, however, it is used as: donezepilo, rivastigmine and galantamine, those that have cognitive functions. New research related to rescue and ornithine, despite this, the curative treatment of the disease remains uncertain.
\end{abstract}

Volume 2 Issue 6 - 2017

\author{
Jesús Bustamante Díaz \\ Faculty of Health Sciences, University of Sucre, Colombia
}

Correspondence: Jesús Bustamante Díaz, aculty of Health Sciences, Medicine Program. Group of Medical and Pharmaceutical Sciences, University of Sucre, Colombia, Tel 3002132322, Email jesusdariol596@hotmail.com

Received: September0I, 2017 | Published: December II, 2017

\section{Introduction}

The third part of elders at 85 years of age will have some type of dementia, all affected, $16 \%$ can be classified as vascular dementia $(\mathrm{VaD})$, for this reason, it is considered the second neuropathology causing dementia in older adults. ${ }^{1}$ It defines a gross mode with the presentation of the problems of reasoning and the commitment of the planning, judgment and memory, product of an alteration in the secondary cerebral circulation a cerebrovascular accident. ${ }^{2}$ Estimates a prevalence in Latin America of $0.6 \%$ To $2.1 \%$ For individuals $>$ 65 years 1 ; In the United States, a prevalence of $0.98 \%$, between 80 89 years of $4.09 \%$ and in $>90$ years of $6.10 \%$ is estimated in $71-79$ years, demonstrating that cerebrovascular dysfunction progressively increases after the age of 85 Years It is believed an association between Alzheimer's disease and vascular dementia can be considered, considering a mixed dementia. ${ }^{3}$

The risk factors for vascular dementia are chronic hypertension,4 diabetes mellitus, smoking, $\mathrm{APOE}^{4}$ isoforms, obesity, age ${ }^{5}$ late-onset depression $^{6}$ and hypercholesterolemia. ${ }^{7}$ The onset of $\mathrm{VaD}$ is due to any vascular injury (ischemia) That affects brain functional tissue causing gliosis and demyelination. Atherosclerosis, thrombosis or valvulopathies are the direct causes of ischemia, ${ }^{8}$ depending on the origin of the lesion we include a spectrum of $\mathrm{VaD}$ subtypes such as multi-infarct dementia, post-stroke dementia, dementia due to disease of small vessels subcortical ischemic vascular disease, dementia Of hypoperfusion and hereditary vascular dementia. ${ }^{9}$ The dementia due to disease of small vessels is subclassified in Binswanger's disease, amyloid angiopathy with hemorrhages, CADASIL (Cerebral Autosomal Dominant Arteriopathy with Subcortical Infarts and Leukoencephalopathy). ${ }^{10}$

Therefore, it is estimated that the causal origin of cognitive deterioration are cerebrovascular disorders; The cerebral blood vessels are fundamental for the supply of oxygen and nutrients, in addition, they participate in the trophic signaling that establishes connections between the neurons and the glia with the cerebrovascular cells, therefore, the vascular damage interrupts homeostatic interactions, focusing on the white matter, area of greatest risk of vascular damage. ${ }^{11}$ The morphological changes characteristic of $\mathrm{VaD}$ involve globally: infarcts in cortical and subcortical arterial territories, lesions in the aforementioned white matter, and the hippocampus ${ }^{12}$ this is translated into progressive deterioration of memory, executive dysregulation (difficulty in planning and organizing), aphasia (Dysfunction in the ability to produce and understand complex movements and gesticulations), agnosia (difficulty in visuospatial processing), neuroconductive symptoms (agitation, apathy and disinhibition) ${ }^{13}$ disability, Depression and behavioral changes. ${ }^{14}$

For the diagnosis of Vascular dementia, the NINDS - AIREN criteria described in Table $1^{15,16}$ are used. New studies support the use of biomarkers as a diagnostic guideline, among which microRNAs have been proposed: miR-409-3p, MiR-502-3p, miR-486-5p and miR-451a, found in plasma of patients with VaD and cerebrovascular disease of small vessels ${ }^{17}$ however, Quinn, et al. show that there is no strong evidence for the early use of biomarkers in the diagnosis of $\mathrm{VaD}$, equally maximizing the importance of the standard diagnostic approach and strategy, which has worked well. ${ }^{18}$

Table I Diagnostic criteria of vascular dementia taken from NINDS - AIREN

\begin{tabular}{lll}
\hline $\begin{array}{l}\text { Possible vascular } \\
\text { dementia }\end{array}$ & $\begin{array}{l}\text { Vascular dementia } \\
\text { likely }\end{array}$ & $\begin{array}{l}\text { Vascular dementia } \\
\text { defined }\end{array}$
\end{tabular}

Focal, non-

neuroimaging

neurological signs

that exhibit cerebral

Prematurity of gait.

Criteria for probable

vascular disease.
No temporal
association between
dementia and stroke.

Dementia onset with evidence of cerebral vascular disease.

\section{Reports of instability Vascular disease and frequent falls. confirmed by biopsy or necropsy.}

No histological lesions suggestive of Alzheimer's disease (although there may be mixed dementia).

Absence of other Psuedobulbar palsy. diseases as a cause of dementia.

Personality and mood with evidence of alterations. 
With respect to the treatment, the acetylcholinesterase inhibitors are used with unusual expectations, such as: Donezepilo, Rivastigmine and Galantamina, also N-methyl-D-Aspartate inhibitors like memantine are used, however, their effectiveness Has not been shown to be sufficient to eliminate VaD -derived disorders. ${ }^{19}$ Controversially, some authors affirm that the aforementioned drugs lack treatable and identifiable therapeutic objectives, this being sustainable in the real ignorance about the injection of cerebrovascular deterioration with the secondary cognitive disorder. ${ }^{20}$

Studies have therefore been carried out to identify new molecules involved in the development of the disease. One of these studies describes the use of nanoparticles of Solid lipids loaded with Resveratrol (R-SLNs) in murine for reduction of mitochondrial reactive oxygen, lipid peroxidation and protein carbonyls. In addition, there is a decrease in levels of hypoxia-inducible factor $1 \alpha$ (HIF-1 $\alpha$ ). In this way, R-SLNs promises to be an innovative therapeutic strategy in $\mathrm{VaD} .{ }^{21}$ Other investigations suggest the use of psychostimulants such as citicoline and vinpocetine, supplements as actovegin, and finally, therapies with herbal derivatives, within these the huperzine A, however, its favorable effects are not clearly elucidated. Lifestyle modifying therapies, a balanced diet, exercise and control over vascular risk factors, it should not be forgotten that their execution plays an important role in the prevention and treatment of $\mathrm{VaD} .{ }^{22}$ Finally to understand that vascular dementia is a pathology of difficult management and uncertain prognosis, to date only treatable to improve the cognitive abilities until the causal factor of the disease degrades them volitionally.

\section{Acknowledgements}

None.

\section{Conflict of interest}

Author declare that there is no conflict of interest in the doing of the present manuscript.

\section{References}

1. Bayona H. Demencia Vascular: Un Reto Para El Clínico. Acta Neurol Colombia. 2010;26(3):69-77.

2. Khan A, Kalaria Rn, Corbett A, et al. Update on Vascular Dementia. $J$ Geriatr Psychiatry Neurol. 2016;29(5):281-301.

3. Smith E. Clinical Presentations And Epidemiology of Vascular Dementia. Clinical Science. 2017;131(11):1059-1068.

4. Reig L, Antón I, Sánchez P. Relación Entre Hipertensión Arterial Y La Demencia. Hipertens Riesgo Vasc. 2011;28(5-6):182-195.

5. Tariq S, Barber Pa. Dementia Risk and Prevention by Targeting Modifiable Vascular Risk Factors. J Neurochem. 2017.
6. Pineda A, Rendón Jc, Toro E, et al. Depresión De Aparición Tardía Y Su Relación Con La Demencia Vascular En El Anciano. Méd Uis. 2014;27(2):51-58.

7. Appleton JP, Scutt P, Sprigg N, et al. Hypercholesterolaemia And Vascular Dementia. Clin Sci (Lond). 2017;131(14):1561-1578.

8. Uwagbai O, Kalish V. Vascular dementia. Statpearls. Lancet. 2017;386(10004):1698-1706.

9. Muñoz Mj, Espinosa D. Deterioro Cognitivo Y Demencia De Origen Vascular. Revista Mexicana De Neurociencia. 2016;17(6):85-96.

10. Romero A, Fernández E, López J, et al. Actualización En Diagnóstico Y Manejo De Las Demencias. Aportes Prácticos En Nuestro Contexto. Revista Finlay. 2012;2(1):76-87.

11. Iadecola C. The Pathobiology Of Vascular Dementia. Neuron. 2013;80(4):844-866.

12. Jellinger Ka. Avances En La Fisiopatología De La Demencia Vascular. Rev Esp Geriatr Gerontol. 2004;39(1):41-49.

13. Rodríguez P1, Rodríguez D. Diagnóstico Del Deterioro Cognitivo Vascular Y Sus Principales Categorías. Neurología. 2015;30(4):223-239.

14. Wren P, Hill D, Lockhart A. Mechanisms Of Vascular Disease In Dementia: What Does Industry Want To Know? Clinical Science. 2017;131(9):799-802.

15. Jato M. Demencia Vascular. Alzheimer. Realidades E Investigación En Demencia. 2001;20:4-11.

16. Román Gc, Tatemichi TK, Erkinjuntti T, et al. Vascular Dementia: Diagnostic Criteria For Research Studies: Report Of The Ninds-Airen International Workshop. Neurology. 1993;43(2):250-260.

17. Prabhakar P, Chandra Sr, Christopher R. Circulating Micrornas As Potential Biomarkers For The Identification Of Vascular Dementia Due To Cerebral Small Vessel Disease. Age Ageing. 2017;46(5):861-864.

18. Quinn T, Mccleery J. Diagnosis In Vascular Dementia, Applying 'Cochrane Diagnosis Rules' To 'Dementia Diagnostic Tools'. Clinical Science. 2017;131(8):729-732.

19. Yoshimura M, Nishida K, Takekita Y, et al. Vascular Dementia: An Update. Nihon Rinsho. 2016;74(3):489-494.

20. O'brien J, Thomas A. Vascular Dementia. Lancet. 2015;386(10004):1698-1706.

21. Yadav A, Sunkaria A, Singhal N, et al. Resveratrol Loaded Solid Lipid Nanoparticles Attenuate Mitochondrial Oxidative Stress In Vascular Dementia By Activating Nrf2/Ho-1 Pathway. Neurochem Int. 2017;S019 7-0186(17):30154-30158.

22. Farooq M, Min J, Goshgarian C, et al. Pharmacotherapy For Vascular Cognitive Impairment. Cns Drugs. 2017;31(9):759-776. 